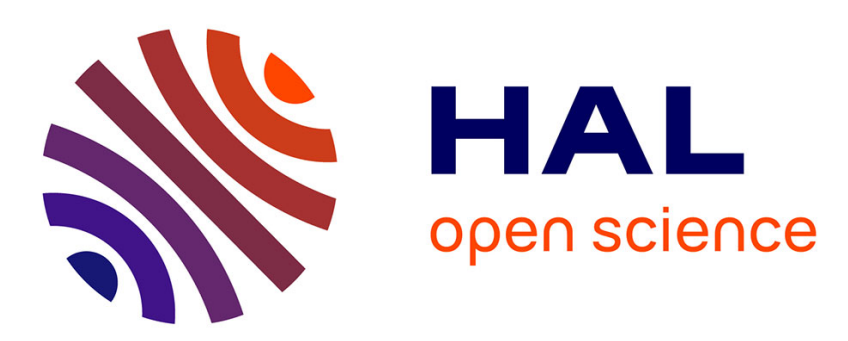

\title{
Contribution of image analysis to the description of enzymatic degradation kinetics for particulate food material
}

\author{
Marie-Francoise Devaux, Ina Taralova, Jacques Lévy Véhel, Estelle Bonnin, \\ Jean-Francois Thibault, Fabienne Guillon
}

\section{To cite this version:}

Marie-Francoise Devaux, Ina Taralova, Jacques Lévy Véhel, Estelle Bonnin, Jean-Francois Thibault, et al.. Contribution of image analysis to the description of enzymatic degradation kinetics for particulate food material. International Journal of Food Engineering, 2006, 77 (4), pp.1096-1107. hal-00539282

\section{HAL Id: hal-00539282 \\ https://hal.science/hal-00539282}

Submitted on 24 Nov 2010

HAL is a multi-disciplinary open access archive for the deposit and dissemination of scientific research documents, whether they are published or not. The documents may come from teaching and research institutions in France or abroad, or from public or private research centers.
L'archive ouverte pluridisciplinaire HAL, est destinée au dépôt et à la diffusion de documents scientifiques de niveau recherche, publiés ou non, émanant des établissements d'enseignement et de recherche français ou étrangers, des laboratoires publics ou privés. 
Contribution of image analysis to the description of enzymatic degradation kinetics for particulate food material

M.-F. Devaux ${ }^{1 *}$, I. Taralova ${ }^{2}$, J. Levy-Vehel $^{2}$, E. Bonnin ${ }^{1}$, J .-F. Thibault ${ }^{1}$, F. Guillon ${ }^{1}$

1 : Unité de Recherche sur les Polysaccharides, leurs Organisations et Interactions. INRA. BP 71627, 44316 Nantes Cedex 03

2 : IRCCYN, Ecole Centrale de Nantes. 1 rue de la Noë - 44321 Nantes Cedex 03

*Corresponding author: M.-F. Devaux:

Fax : 33 (0) 2406752 29. Email : marie-francoise.devaux@nantes.inra.fr 
Abstract

The objective of the present work was to relate the physical evolution quantified by image analysis to the chemical transformation of beet pulp particles during enzymatic degradation. Beet pulps were degraded into a torus reactor equipped for visualisation. Pectinolytic and cellulolytic enzymes were used separately or in combination. Two global image analysis techniques were tested to characterise the size distribution of overlapping particles. Granulometric curves were extracted by mathematical morphology and a regularisation dimension was assessed by fractal analysis. Both techniques proved efficient to follow particle size evolution during degradation. When using cellulolytic enzymes alone, no chemical or physical evolution was observed. When using pectinolytic enzymes, a chemical modification occurred without any physical evolution. Particles physically disappeared when both enzymes were used. The chemical and physical evolutions of particles during degradation were interpreted taking into account the current model of molecular arrangement of primary cell walls.

Key words: enzymatic degradation, image analysis, mathematical morphology, fractal analysis 


\section{Introduction}

Plant cell wall degrading enzymes are largely exploited in agricultural and industrial processes as processing aid in food and non-food industry. Enzymatic compared to chemical treatments offer several advantages: they have low energy impact and are not detrimental to the environment. The products and derived products can be regarded as "natural"(EC directive 88/388). Though largely validated for industrial purpose, research concerning the degradation of plant cell wall through enzymes is still active and aim at a better understanding on the chemical basis of enzymatic degrading process and on their biochemical limits.

When enzymes interact with complex solid substrates, a complete analysis would have to consider the physical structure in addition to the biochemical evolution. Few studies report the effect of enzyme degradation on the microstructure of plant cell walls (Dongowski, 2001) and no papers were found concerning the evolution at a macroscopic scale. In most applications, at the initial stage of reaction, the plant materials are under the form of particles composed of portions of tissues or fragmented cell walls. When submitted to enzyme action, particles may be either eroded, or fragmented, producing a size reduction. This evolution depends on the substrate properties, i.e. porosity, surface properties of the particles and cell walls, local chemical structure, as well as on the enzymes individual activity and synergy. Following particle size distributions during degradation jointly with the biochemical modifications would provide a first insight both in the substrate structure and the enzyme mode of action.

Following reaction kinetics can be achieved by sampling at given time or by using sensor in order to perform online measurement without external modification or interruption of the reaction. Laser light diffraction can be used for this purpose and apparatus are proposed for industrial on-line control (Witt \& Röthele, 1988). An alternative is to use a CCD video camera to visualise the particles and to extract size distribution by image analysis techniques. Several papers report the use of imaging to follow the evolution of the physical state in a reactor (Mas \& Ghommidh, 2001, 
Sarker, Bertrand, Chtioui \& Popineau, 1998). Observing enzymatic degradations usually performed in stirred-tank reactor was a tricky challenge without sampling in the media. Alternative reactors based on a torus geometry have been proposed to achieve enzymatic hydrolyses, the reactive media circulating into the torus directed by a propeller (Nouri, Legrand, Popineau \& Belleville, 1997). Among the advantages of such reactors are pointed out their easy scale-up, their mixing behaviour that prevents deposition of material on the wall (Belleville, Nouri \& Legrand, 1992). In the present work, an additional advantage was found in the possibility to adapt the system for visualisation. For this purpose, a prototype has been built from a torus basis stretched to include a window from which particles can be observed (Devaux, Rival, Sire, Papineau \& Guillon, 1998). Using this system, images could be automatically acquired on-line and were next processed for particle size characterisation.

Size and morphology using image analysis are usually quantified after individual segmentation of the particles, their area, length and elongation being measured. Enzymatic hydrolyses are generally realised in concentrated media. In such conditions, particles may be densely packed and difficult to segment and isolate individually using fully automatic procedure. Another approach consists in performing a global characterisation of particles using image texture description. Image texture can be defined as the spatial arrangement of grey level in images. In this context, small particles produce more frequent grey level changes inducing a finer texture than large particles. Several methods have been proposed for extracting textural features from images (Haralick, 1979) among which some have been proposed to characterise particle size. Cooccurrence features have proved efficient for correlation with the mean particle diameter and for quantifying changes in yeast floc size during continuous fermentation (Mas et al., 2001). Constant grey level run length has been applied for the characterisation of bulk pea powders (Bertrand, Robert, Melcion \& Sire, 1991). 
Mathematical morphology transformations have been applied to extract granulometric information from grey level images (Michelland, Schiborr, Coster, Mordike \& Chermant, 1989, Devaux, Melcion \& Le Deschault De Monredon, 1997). All these works show that textural features can be advantageously applied in context where particles could hardly been automatically individualised. In addition, Novales, Guillaume, Devaux \& Chaurand (1998) have found that these techniques were at least equally efficient for size characterisation of in-flow milling product for which individual segmentation could be performed.

In recent years, there has been an increasing interest in the field of fractal methods to describe structures in the food-processing domain. The reported food applications of fractals mainly dealt with the characterization of the contours of binarised particles such as agglomerated instant coffee particles (Nuebel \& Peleg, 1994) or ice crystals (Hagiwara, Wang, Suzuki \& Takai, 2002). Gels have been characterised by fractal image analysis after binarisation such as fats crystal network (Narine \& Marangoni, 1999) or particulate protein gels (Marangoni, Barbut, McGauley, Marcone \& Narine, 2000, Pugnaloni, Matia-Merino \& Dickinson, 2005). Fractal analysis has also been developed within the context of image texture analysis. Quevedo, Carlos, Aguilera \& Cadoche (2002) applied the technique to describe food surfaces. They showed that the fractal dimension increased monotonically with increased roughness (i.e. grain size and visual texture) of sandpaper.

The objective of the present work was to relate the physical evolution during enzymatic degradation to the chemical transformation. Beet pulps were chosen as a model substrate for particulate plant material. They are mainly constituted of cell walls and composed of pectins and cellulose (Thibault, Renard \& Guillon, 1994). The enzymatic degradation of beet pulps through pectinolytic and cellulolytic enzymes has been largely described to find issues with high adding value (Micard, Renard \&Thibault, 1996, Bonnin, Grangé, Lesage-Meesen, Asther \&Thibault 2000). Until now, no attention was paid to the physical evolution of the substrate during the reactions. In the present paper, two techniques, mathematical morphology and fractal analysis, were tested for 
their ability to describe particle size during enzymatic degradation. Mathematical morphology was chosen for its ability to extract granulometric distribution directly interpretable as particle size characterisation. Fractal analysis was tested as a first attempt to correlate the fractal dimension to a particulate structure and to its evolution during enzymatic degradation.

\section{Material and Methods}

\section{Sugar beet pulp}

The reactions were studied for dry beet pulp (Lyven, France) grounded using a Retsch Gmb $\mathrm{H}$ grinder (Germany). The sieve fraction between 410 and $500 \mu \mathrm{m}$ was chosen for the analysis. The dry matter of the ground beet pulp particles was $92 \%$. The sugar content of the raw pulp is given in table 1. Galacturonic acids and arabinose reveal the initial amount of pectins and glucose the amount of cellulose. Other constituents than polysaccharides were not analysed. They are known to be composed of ashes, proteins, and lignin (Micard et al., 1996).

\section{Enzymatic preparations}

The pectinolytic mixture SP 584 (Aspergillus niger) and the cellulolytic mixture Celluclast $1.5 \mathrm{~L}$ (Trichoderma reesei) were obtained from Novo NordiskA/S (Bagsvaerd, Denmark).

\section{Description of the torus reactor}

The reactor used was a prototype especially designed at INRA (Nantes) to visualise dietary fibre particles during enzymatic degradation. A stirring system and a thermostatic control were necessary to provide appropriate conditions to achieve the reactions. In addition, the reactor had to comprise a system for lighting and visualising the particles. Figure 1 shows the experimental apparatus.

The reactor was constructed from a piece of aluminium with a torus geometry basis. The radius was $65.5 \mathrm{~mm}$ and the inner section of the torus was semi-circular with a radius of $25 \mathrm{~mm}$. The useful 
volume was $230 \mathrm{~cm}^{3}$. The torus geometry has been distorted in order to build a circular visualisation window while preserving the section volume constant all along the torus. A threeblade screw driven by a variable speed motor ensured the stirring. Three flat resistances have been stuck under the aluminium basis in order to warm the solution. A regulator controlled the temperature measured by the thermocouple probe into the reactor. The top of the reactor was made of transparent polycarbonate and the visualisation window was a neutral video filter $(\mathrm{r}=25 \mathrm{~mm})$.

The lighting of the samples has been designed in order to diffuse light through the particles. Twelve red diodes $(\lambda=660 \mathrm{~nm}, 3000 \mathrm{mcd})$ were enclosed with an orientation of $45^{\circ}$ into the aluminium basis to form a ringlight under the visualisation window. The background of the visualisation window was painted in black colour. A fibre optic ringlight was positioned over the visualisation window in order to improve the general brightness.

The reactor was linked to a command board that made it possible to control the stirring speed, the diode intensity and the temperature. The filling was achieved after locking the top by slowly pumping water through a tap in order to avoid air bubble formation.

\section{Enzymatic degradation}

Four kinds of reactions were compared: a reference experiment without enzyme, and three enzymatic reactions with pectinolytic enzymes, with cellulolytic enzymes, and with both enzymatic mixtures. SP584 contained several pectinolytic enzymes. It was chosen because it has high polygalacturonase activities and was only slightly active on cellulose (Micard et al., 1996). Celluclast $1.5 \mathrm{~L}$ contained several cellulolytic enzymes and was found efficient in degrading cellulose rich materials from sugar beet pulp (Bonnin et al., 2000).

The reference experiment and all enzymatic digestions were repeated three times and were conducted as follows. $1.2 \mathrm{~g}$ of ground pulp were hydrated during one night in $30 \mathrm{~cm}^{3}$ of permuted water to get a steady initial particle size after swelling. Hydrated pulps were put into the reactor and 
the volume was completed to $230 \mathrm{~cm}^{3}$. Enzymes were added in a proportion of $1 \%$ of pulp dry matter. Temperature was set to $37^{\circ} \mathrm{C}$. The particles were stirred during all the reaction and moved continuously in the torus. The motor speed was chosen to ensure a circulation of the particles without settling at the bottom of the torus.

The reactions were conducted during 24 hours. Samples of $1.7 \mathrm{ml}$ hydrolysates were taken at times 0, $30 \mathrm{~min}, 1 \mathrm{~h}, 1 \mathrm{~h} 30,2 \mathrm{~h}, 3 \mathrm{~h}, 4 \mathrm{~h}, 6 \mathrm{~h}, 8 \mathrm{~h}, 10 \mathrm{~h}$ and $24 \mathrm{~h}$. Equivalent volume of permuted water was added to maintain constant the liquid volume of the reactor and avoid the generation of air bubbles that would interfere with image analysis of particles. The hydrolysates were boiled for 10 min to inactivate enzymes and centrifuged $(800 \mathrm{x} \mathrm{g}, 15 \mathrm{~min})$. Supernatants were analysed for uronic acid and neutrals sugars by colorimetry. After $24 \mathrm{~h}$, residues were isolated by centrifugation, washed with water, dried by solvent exchange, and weighted. This residual material was ground in liquid nitrogen and analysed for uronic acid and individual neutral sugars by gas liquid chromatography.

Some wet residual particles were taken at the end of the reaction to characterise their physical structure. Particles were stained $(10 \mathrm{~min})$ with $0.02 \%$ acridin orange (CI46005) in $0.1 \mathrm{mol.L^{-1 }}$ phosphate buffer (pH 7). They were observed by confocal laser scanning microscopy (Zeiss LSM 410 confocal inverted microscope, Zeiss, Lepecq, France) using a 40x/1.2 water immersion objective. An argon laser operating at $488 \mathrm{~nm}$ wavelength was used as the excitation source and the fluorescent signal $>515 \mathrm{~nm}$ was collected.

\section{Analytical methods}

Uronic acids were assayed by an automated metahydroxybiphenyl method using galacturonic acid as a standard (Thibault, 1979). Total neutral sugars were determined by automated orcinol procedure (Tollier and Robin, 1979) using arabinose as standard after correction for uronic acid interference. Individual neutral sugars were analysed by gas liquid chromatography after hydrolysis 
(Englyst et Cummings, 1984). The pulp and residues were first prehydrolysed $1 \mathrm{~h}$ in $72 \% \mathrm{H}_{2} \mathrm{SO}_{4}$ at room temperature.

\section{Image acquisition}

Images of the particles had to be acquired during the degradation process, while the particles were moving along the torus. For this purpose, a full frame camera SONY XC $8500 \mathrm{CE}$ was used and the

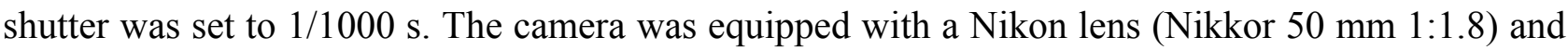
a $12 \mathrm{~mm}$ extension tube and the height was set to observe a $13.3 \mathrm{~mm} \times 10 \mathrm{~mm}$ area. The resulting images were constituted of 768 x 576 pixels, each pixel being of size $17.3 \mu \mathrm{m} \times 17.3 \mu \mathrm{m}$. The levels of grey were coded on 256 values, starting from 0 (black) up to 255 (white). The acquisition was driven by the software VisionStage 1.6fr (Alliance Vision, Mirmande, France).

Images were automatically recorded at times $0,30 \mathrm{~min}, 1 \mathrm{~h}, 1 \mathrm{~h} 30,2 \mathrm{~h}$ and every hour until $24 \mathrm{~h}$. Ten images were acquired at each programmed time. On the course of some experiments, air bubbles could appear caused by some water evaporation. Few images were disturbed and were eliminated from the analysis.

\section{Image processing}

The objective of image processing was to extract quantitative information concerning the evolution of the physical state of the particles during the reaction, and mainly the particle size. Examples of images shown in Figure 2 show that particles largely overlapped making the segmentation of individuals somewhat difficult. Quantification of particle size was therefore performed directly from grey level images. Two kinds of image processing tools were used: mathematical morphology and fractal analysis.

Morphological granulometric curves 
Mathematical Morphology is a set of procedures based on the comparison of portions of images to elements of given size and shape called "structuring elements" (Serra, 1982). The basic transformations are "erosion", "dilation", "opening" and "closing". Erosion causes a reduction of white object and dilation an increase. The effect of opening (erosion followed by dilation) is to remove white objects for which at least one dimension is smaller than the structuring element ones while preserving the size of the remaining objects. This property makes opening comparable to a sieving in area of the objects in the image. By applying openings of increasing size, a granulometric characterisation of the image can be derived. The procedure, initially developed for binary images, has also been used for determining size distributions from grey level images (Michelland et al., 1989). The principle is briefly described.

Opening causes a decrease of the sum of the grey level in the image $V$ depending on the amount of white objects removed by the operation. By applying openings of increasing size, objects progressively disappear and a curve of the sum of grey level $V$ according to the size of the structuring element is built. This raw curve is normalised according to the initial value and derived to obtain a curve comparable to a size distribution:

$$
g(i)=\frac{V(i)-V(i+1)}{V(\text { initial })-V(\text { final })}
$$

where $V$ (initial) is the volume of the original image, $V$ (final) the volume at the last opening step, $i$ is one of the opening steps. The $g$ curves are called morphological granulometric curve and measure the proportion of grey level that are modified between two successive opening steps.

In the present work, the structuring element was the usual square with a reference pixel at the centre. At the first step, the size of the element was $3 \times 3$ pixels, at step $2,5 \times 5$ pixels, etc... The size of the structuring element can be expressed in $\mu \mathrm{m}$ rather than in pixels and the granulometric curves can be drawn relatively to the size rather than to the opening step. Thirty-five opening steps were applied that amounted to study particle size between $52 \times 52 \mu \mathrm{m}^{2}$ to $1228 \times 1228 \mu \mathrm{m}^{2}$. The 
final granulometric curves were obtained by averaging the individual curves of the images acquired at each time.

Images were corrected for non-uniform illumination before morphological analysis. A top hat transformation was applied using a 36 × 36 squared structuring element in order to remove nonuniform background. A suited white reference was calculated for each image in order to give all particles similar brightness. Each image was dilated using a 36 x 36 squared structuring element and all values under 100 were set to the grey level value 100 . Normalisation was achieved by dividing the original image by the white reference obtained and grey levels were adjusted from zero to 255 . Granulometric curves were compared using Principal Component Analysis (Jolliffe, 1986), which has been proved an efficient technique to compare continuous signal such as spectra (Robert, Devaux and Bertrand, 1996).

The morphological analysis was developed using procedures from the software Aphelion 3.0E (ADCIS, Hérouville-Saint-Clair, France). Principal component analysis was applied using the PLS_Toolbox 2.0 (Eigenvector Research, USA) within the MATLAB environment (The MATHWORKS, USA).

\section{Fractal analysis: regularization Dimension}

Fractional dimensions are one of the best-known parts of fractal analysis. The principle of the fractional measure called "regularization dimension" is the following (Rouef and Levy-Vehel, 1998). Let $I(x, y)$ denote the image $(I(x, y)$ is the grey level intensity of pixel $(x, y)) . I$ is smoothed (regularized) by convolution with, e.g., a gaussian kernel $K_{\sigma}$ of variance $\sigma$. Let us denote by $I_{\sigma}$ the regularized image $I_{\sigma}=K_{\sigma} * I$. Assume that $I$ is so irregular that the surface $(x, y, I(x, y))$ in $\mathfrak{R}^{3}$ has infinite area. When images $I_{\sigma}$ are smoothed for all $\sigma>0$, their surfaces $(x, y, I(x, y))$ have finite area $S_{\sigma}$. Furthermore, when $\sigma$ tends to zero, $I_{\sigma}$ tends to $I$, and $S_{\sigma}$ tends to infinity. The regularization dimension $\operatorname{dim}_{R}$ measures the speed of convergence of $S_{\sigma}$ to infinity. 
Formally, one sets:

$$
\operatorname{dim}_{R}=1+\lim _{\sigma \rightarrow 0} \frac{\log \left(S_{\sigma}\right)}{-\log \sigma}
$$

When the limit above does not exist, one considers upper and lower regularization dimensions $\overline{\operatorname{dim}_{R}}$ and $\underline{\operatorname{dim}_{R}}$ defined as follows :

$$
\begin{aligned}
& \overline{\operatorname{dim}_{R}}=1+\varlimsup_{\sigma \rightarrow 0} \frac{\log \left(S_{\sigma}\right)}{-\log \sigma} \\
& \underline{\operatorname{dim}_{R}}=1+\underset{\sigma \rightarrow 0}{\lim } \frac{\log \left(S_{\sigma}\right)}{-\log \sigma}
\end{aligned}
$$

For the numerical calculation of the regularization dimension, the FRACLAB toolbox has been used (http://www.irccyn.ec-nantes fr/irccyn/Projets/FracLab/Fraclab.html). In practice, one cannot compute a limit. Instead, a finite range [Nmin, Nmax] has to be chosen for the amount of smoothing, which is governed by the variance $\sigma$ of the gaussian kernel $K_{\sigma} \cdot$ Nmin and Nmax define the bounds between which $\sigma$ varies, expressed in pixel units. Low values of Nmin and Nmax correspond to image processing in high frequencies since the width of the smoothing kernel is small. On the contrary, great Nmin and Nmax values correspond to smoothing with a larger kernel and therefore the image will be processed at low frequencies. An additional parameter selects the number of smoothed curves computed between Nmin and Nmax. The fractional dimension is estimated through a least square linear regression of $\log S_{\sigma}$ versus $\sigma$ assuming that the graph of $\left(\log \sigma, \log S_{\sigma}\right)$ is $\operatorname{linear}$. When this is not the case, a special type of regression has been applied that is able to estimate an inferior limit Linf or a superior limit Lsup, giving $\overline{\operatorname{dim}_{R}}$ or $\operatorname{dim}_{R}$ (Legrand \& Levy-Vehel, 2004). An example of the use of FRACLAB for calculating the regularization dimension is shown in Figure 3. The regularization dimension is given by the slope of the graph of the regression and therefore makes sense only for segments of the graph exhibiting linear behaviour. For the considered example, two different parts with linear behaviour may be observed: One for low frequencies and another for high frequencies. Although this is by no means a general fact, in the 
pictured case as well as for all images considered in this study, the two slopes obtained corresponded in fact to Linf and Lsup: the points to the left of the graph (high frequencies) line up with a small slope, while the points to the right (high frequencies) line up with a larger (absolute) slope.

\section{Results and discussion}

\section{$\underline{\text { Chemical evolution }}$}

The reference reaction and the three enzymatic degradations were carried out for 24 hours, during which samples from the reaction media were withdrawn and images were acquired. At the end of the reactions, the residual insoluble materials were weighted, the yield of residues being representative of the degrees of degradation (Micard et al., 1996). For the reference and the cellulolytic experiments, $76 \pm 3 \%$ and $75 \pm 4 \%$ of the initial dry matter were recovered, respectively. The values were $31 \pm 4 \%$ after the pectinolytic enzyme action and $12 \pm 1 \%$ using pectinolytic and cellulolytic enzymes in combination. The values observed for the reference experiments suggest that at least $20 \%$ of dry matter were made soluble without any enzymes. This result is in agreement with previous works that reported a spontaneous water solubilisation of $17 \%$ of dry matter for beet fibre (Thibault \& Rouau, 1990). The cellulolytic treatment did not bring further solubilisation. Using pectinolytic enzymes, much less solid materials were recovered.

The sugar composition of the residues is given in Table 1. Glucose was the main component of the SP584 residues. Expressed in percentage of initial sugar content, most of the glucose (94\%), mannose $(90 \%)$ and to a lesser extent xylose $(40 \%)$ were recovered in the residues. In contrast, galacturonic acid, arabinose and galactose were extensively released. When both pectinolytic and cellulolytic activities were present, most of the glucose and to a lesser extent mannose and xylose were solubilised. Only $22 \%$ of the residue left after $24 \mathrm{~h}$ hydrolysis was composed of 
polysaccharides. The extent of the chemical degradation in the torus reactor was in agreement with that reported by Micard et al. (1996).

SP584 enzymes break down beet pectins mainly into galacturonic acids and arabinose and Cellulast 1.5L enzymes produce cellobiose and glucose from cellulose. The release of neutral sugars and uronic acid from sugar beet was measured on the time course as tracers of the enzymatic degradations. Results are given in percentage of sugar solubilisation according to time (Figure 4). The solubilisation curves for cellulolytic enzymes were confused with the reference experiment attesting that no degradation occurred. The action of pectinolytic enzymes produced an almost complete solubilisation of galacturonic acids (around $90 \%$ ) and a partial one for neutral sugars (around $50 \%$ ). Degradation was rapid during the first 3 hours and was completed after 6 hours. The combined action of pectinolytic and cellulolytic increased the solubilisation values for neutral sugars up to $70 \%$ and speeded the reaction completion, as the maximum solubilisation was obtained after 3 hours. The difference of solubilisation when compared to pectinolytic enzyme action alone was found significant by variance analysis and corresponded to the cellulose content of beet pulp.

\section{$\underline{\text { Images during degradation }}$}

Figure 2 shows examples of images acquired during enzymatic degradation for the four kinds of reaction studied. Images proved that the agitation in the reactor lead to a homogeneous distribution of the particles under the visualisation window. At the concentration studied, images clearly revealed the particulate nature of the material though particles overlapped and could not be all identified individually. No evolution of the particles was visible during the reference and the cellulolytic reactions. When using pectinolytic enzymes, particles seemed preserved while the solution was slightly made opaque. When both kinds of enzymes were used, a physical degradation of the particles occurred together with the solution significantly made opaque. The chemical 
degradation caused when pectinolytic enzymes were used alone did not come with an apparent physical degradation.

\section{Morphological granulometric curves}

Particle size during degradation was studied by mathematical morphology. Figure 5 show examples of granulometric curves assessed at times $0,2 \mathrm{~h}, 4 \mathrm{~h}, 6 \mathrm{~h}, 8 \mathrm{~h}, 10 \mathrm{~h}, 12 \mathrm{~h}$ and $24 \mathrm{~h}$ for the four kinds of experiments. The curves resulted from the averaging of the individual curves calculated for the images recorded at each time. For the reference and cellulolytic experiments, large peaks between 100 and $1000 \mu \mathrm{m}$ were obtained showing no evolution. The maximum was found between 250 and $400 \mu \mathrm{m}$, lower than the original particle size of the dried pulp $(400-510 \mu \mathrm{m})$. The discrepancy can be explained by the fact that particles are removed from the image when their smallest dimensions are lower than the opening size. For dried pulps, particle size was determined from sieving which mainly depend on the largest dimensions and particles were somewhat elongated (Figure 2). In addition, the curves were calculated from grey level images, one individual particle showing different grey levels that generated variations for smaller opening size. Grey level variations were also observed below $100 \mu \mathrm{m}$ and were mainly attributed to variations both into the solution and within the particle surface. Granulometric curves were therefore interpreted for their evolution rather than absolute size distributions.

When using pectinolytic enzymes, the curves were quite similar to the reference experiment. Only a slight variation was observed for time $24 \mathrm{~h}$ with a small shift towards lower size. The particle size evolution when both enzymes were used could be quantified. During degradation, the initial peak clearly shifts towards lower values and disappear after 6 hours to become a truncated size distribution.

Principal component analysis was applied on the data table made by gathering all the curves obtained for the three replicates of each experiment in order to achieve the global comparison of the 
four kinds of reaction. The objective was to visualise all the data acquired in a synthetic way and to reveal the variations in position and shape of the granulometric peaks. In particular, slight variations that could have occurred in the case of the pectinolytic experiments were searched for. Figure 6 show the first principal component scores according to time. Component 1 took into account $97 \%$ of the total variation observed among the curves and mainly described the evolution during degradation observed when combining the two kinds of enzymes. This analysis shows that the particle size diminution began immediately after the beginning of the reaction and was rapid during the first 6 hours. The evolution of the physical structure was not terminated and continued until 24 hours. The three other kinds of experiment were not distinguished. The slight shift observed in Figure 5 for the pectinolytic experiments also corresponded to a slight diminution of the scores observed after 10 hours. The variations could not however be proved significant.

\section{$\underline{\text { Regularization dimension }}$}

A regularization dimension has been calculated for each group of samples and for each hour of the test. Two different fractal behaviours have been observed, for low and for high frequencies. Therefore, upper and lower fractional dimensions have been calculated for each sample. Roughly speaking, the lower fractional dimension measures the irregularity of the distribution since it corresponds to the low frequencies, and the upper fractional dimension measures the irregularity of the individual particle and in the medium surrounding particles since it corresponds to the high frequencies.

Error bars taking into account the standard deviation have been calculated for each test hour. As it can be seen in figure 7 , the error bars had approximately similar small lengths in all considered cases, which testified of the good representation of the data and the relevance of the results. The reference samples of beet pulp (not subjected to enzyme action) showed essentially a constant regularization dimension around 2.44 (Figure 7a). It can be noticed that the results are as 
good for the upper limit Lsup that for the lower limit Linf and on the other hand, the curves corresponding to the upper limit and the lower limit are close, which indicates fractal behaviour at all frequencies. Similar comments could be drawn from the experiment with only cellulolytic enzyme (Figure 7b). No effect on the enzyme decomposition was observed in terms of evolution of the regularization dimension with time. Missing points corresponded to hours for which images were discarded, as bubbles had appeared. In these cases, there were not 10 images per hour and the data are not shown.

Using pectinolytic enzyme only (Figure 7c), there was a correlation between the regularization dimension and the enzymatic decomposition but the increase in the regularization dimension with time was small (2.5 at the end of the experiment). More precisely, one can easily distinguish two different behaviours on the images corresponding to the first six hours and the others. As shown from the chemical data, this enzyme acted only during the first six hours. After the $6^{\text {th }}$ hour, the particles may have become a little fragile and prone to the physical treatment, which could explain the increase in the irregularity of the image, measured by the fractional dimension. As in the case of Figure 7a (no enzymes), the upper limit and the lower limit were quite close to each other (almost equal), which indicated again fractal behaviour at all frequencies.

In the case of the combination of pectinolytic and cellulolytic enzymes (Figure 7d) a strong evolution of the regularization dimension was observed. The increase was slightly larger for high frequencies (upper limit). At the end of the reaction, the irregularity of the particles and of the medium surrounding particles was predominant in the roughness of the image (after hour 16). In addition, for the last hours, the images did not exhibit a fractal structure at all frequencies, since the lower and upper limits were significantly different. 


\section{Discussion}

The objective of the work was to describe enzymatic degradation of solid particulate materials by considering both the chemical and the physical evolutions. The kinetics were characterised by the sugar released on the time course and by the changes in the particulate structure visualised through images. A torus-based reactor has been developed for the on line image acquisition of particles during reactions at a macroscopic scale. The system was efficient to observe a large number of particles in a statistical way without any human intervention. The chemical evolution was measured after manual sampling of the solution in the reactor. Further development of the machine could be to associate an automatic sampling towards an analytical apparatus such as a chromatograph. In addition, such reactor can be equipped with various probes such as conductimetric probes, electrode, or $\mathrm{pH}$ probes (Nouri et al, 1997).

Particle size evolution was quantified by image analysis using global techniques from mathematical morphology and fractal analysis. Both techniques proved efficient to follow size evolution during enzymatic degradation. The alternative approach would have consisted in segmenting individual particles and would have required a much lower concentration of particles in the solution. Mathematical morphology openings are well adapted to study particle size as they can be compared to a sieving of the image. The granulometric curves extracted from grey level images can be regarded as classical granulometric distributions. The major point is that they are related to the area rather than to the volume or mass of particles. Though the size could be under-estimated in comparison to other methods and in particular sieving, curves are easy to interpret in relation to particle size evolution.

The regularization dimension could be used as a successful tool to follow the particle size evolution during enzymatic degradation. When no particle size evolution occurred, the fractional dimension was constant. When particles were highly degraded by the two kinds of enzymes, the regularisation dimension varied continuously with time. In the case of pectinolytic action alone, yet the reaction 
was over after the first few hours, the fractal dimension significantly increased, indicating that a physical decomposition was still going on. The technique depends on the choice of the size of the smoothing parameter (wide or narrow kernel). It is possible to refine the study, and to select either the high frequency properties, i.e. the irregularity of the individual particle or the surrounding medium, or the low frequency properties, i.e. the irregularity of the particle distribution in the image.

Both techniques were proved relevant to quantify the physical evolution of the particles during the enzymatic degradation. Mathematical morphology provides a measure easy to interpret in terms of granulometry. Regularisation dimensions were nicely related to particle size and made it possible to reveal a significant evolution of the system when using pectinolytic enzymes alone.

Considering both chemical analysis and the evolution of the physical state quantified by image analysis, conclusions could be drawn for the four kind of enzymatic reactions. The experiment with no enzymes showed that no evolution was observed either chemical or physical. Using cellulolytic enzymes alone, also no chemical or physical evolution occurred. When using pectinolytic enzymes, a chemical evolution was observed which did not come with an apparent physical evolution at the macroscopic scale. A particulate structure remained while the solution was made more opaque. Combining both enzyme activities, pectin and cellulose constituents were made soluble together with a particle physical degradation.

The chemical evolution of beet pulp occurred only when pectinolytic enzymes were present. The current models proposed for molecular arrangement describe the primary cell walls as a cellulose fibre skeleton embedded in the pectin matrix (Carpita \& Gibeaut, 1993). The cellulolytic enzymes could reach the cellulose molecules only when pectin molecules were degraded. The pectin breakdown gives the cellulases access to their substrates thus making the degradation of cellulose possible (Thibault \& Rouau, 1990). 
In presence of both enzymes, the physical degradation of the particles was rapid during the first hours. This evolution went on in a slower way until the 24 hours of reaction, although the chemical evolution was finished after 6 hours. When using pectinolytic enzymes, a slight diminution of the particle size was observed after 10 hours. The evolutions observed after the chemical degradation was completed, may be attributed to a mechanical stress. The stirring system of the reactor was a three-blade propeller that produced low shear stress. This was shown by the reference experiments during which particle size did not changed. Stirring may have however affected particles weakened after enzymatic degradation.

The preservation of a particulate structure after pectin degradation was not expected as pectins are described as involved in cellular adhesion. Results showed that the chemical degradation was almost completed while particles remained. The structure of the residual particles was examined at the microscopic scale. (Figure 8). Sugar beet root is composed of different tissues: storage parenchyma and vascular tissue. On the micrographs are presented particles containing vessels with lignified walls included in parenchymateous tissue. When submitted to pectinolytic enzymes, cell aspect was modified : cell walls were less clear and cell size was reduced. The vessels remained intact and were the only residual particles when both enzymes were used. These results showed that the pectinolytic action modified the microscopic structure of particles but were not able to broke completely the cell connections. This may be explained by two factors. First, other molecules than pectin may be involved in cellular adhesion and second, cellular adhesion may have been modified during beet root processing for sucrose extraction.

\section{Conclusion}

The present work aimed at comparing the chemical and the physical evolution of solid materials when submitted to enzymatic degradation with an application to the enzymatic degradations of beet pulps. Online characterisation into reactors makes it possible to study the kinetics of the reactions at 
a macroscopic scale, close to the process scale. Global image analysis techniques were efficient to characterise the size evolution when particles highly overlapped. Information concerning the physical structure at this scale is useful for a statistical approach and complement biochemistry and microscopic studies. These information are relevant to provide a more complete interpretation of enzymatic degradation. A deeper insight for understanding both enzyme actions and the organisation and interaction between the polymers included in cell wall structure can be gained by this way. 


\section{References}

Belleville, P., Nouri, L. \& Legrand, J. (1992). Mixing characteristics in the torus reactor. Chemical Engineering Journal, 15, 282-289.

Bonnin, E., Grangé, H., Lesage-Meesen, L., Asther, M. \& Thibault, J-F. (2000). Enzymic release of cellobiose from sugar beet pulp, and it use to favour vanillin production in Pycnoporus cinnabarinus from vanillic acid. Carbohydrate Polymers, 41, 143-151.

Bertrand, D., Robert, P., Melcion, J.-P. \& Sire, A. (1991). Characterisation of powders by video image analysis. Powder Technology, 66, 171-176.

Carpita, N. C. \& Gibeaut, D. M. (1993). Structural models of primary cell walls in flowering plants : consistency of molecular structure with the physical properties of the walls during growth. The Plant Journal, 14, 875-884.

Devaux, M.-F., Melcion, J.-P. \& Le Deschault De Monredon, F. (1997). Particle size analysis of bulk powders using mathematical morphology. Powder Technology, 90, 141-147.

Devaux, M.-F., Rival, M., Sire, A., Papineau, P. \& Guillon F. (1998). A reactor for the continuous determination of particle size by image analysis during enzymatic degradation of dietary fibre. In Proceedings of the $7^{\text {th }}$ European Symposium Particle Characterization PARTEC 98. Preprints III (pp. 1005-1014). NürnbergMesse GmbH. Nürnberg, March 10-12.

Dongowski, G. (2001). Enzymatic degradation studies of pectin and cellulose from red beets. Nahrung/Food, 45, 324- 331.

Englyst, H.N. \& Cummings, J.H. (1984). Simplified method for the measurement of total non starch polysaccharides by GL chromatography of constituent sugars as alditol acetates. Analyst, 109, 937942.

Hagiwara, T., Wang, H., Suzuki, T. \& Takai R. (2002). Fractal analysis of ice crystals in frozen food. Journal of Agricultural and Food Chemistry, 50, 3085-3089. 
Haraclick, R. M. (1979). Statistical and structural approaches to texture. Proceedings IEEE, 67, 786-804.

Jolliffe, I.T. (1986). Principal Component Analysis. New York: Springer-Verlag.

Legrand, P. \& Levy Vehel, J. (2004). Signal and image processing with Fraclab. In Fractal 2004. Vancouver, April 4-7.

Marangoni, A. G., Barbut, S., McGauley, S.E., Marcone, M. \& Narine, S. S. (2000). On the structure of particulate gels- the case of salt-induced cold gelation of heat-denatured whey protein isolate. Food Hydrocolloids, 14, 61-74.

Mas, S. \& Ghommidh, C. (2001). On-line measurement of yeast aggregates using image analysis. Biotechnology and Bioengineering, 76, 91-98.

Micard, V., Renard, C. M. G. C \& Thibault, J-F. (1996). Enzymic saccharification of sugar beet pulp. Enzyme and Microbial Technology, 19, 162-170.

Michelland, S., Schiborr, B., Coster, M., Mordike, B. L. \& Chermant, J. L. (1989). Size distribution of granular material from unthresholded images. Journal of Microscopy, 156, 303-311.

Narine, S. \& Marangoni, A. (1999). Microscopic and rheological studies of fat crystal networks, Journal of Crystal Growth, 1315-1319.

Nouri, L., Legrand, J., Popineau, Y. \& Belleville, P. (1997). Enzymatic hydrolysis of wheat proteins. Part 2: comparison of performance of batch-stirred and torus reactor. Chemical Engineering Journal, 65, 195-199.

Novales, B., Guillaume, S., Devaux, M.-F. \& Chaurand, M. (1998). Particle size characterisation of in-flow milling products by video image analysis using global features. Journal of the Science of Food and Agriculture, 78, 187-195.

Nuebel, C. \& Peleg, M. (1994). A Research Note Compressive Stress-Strain Relationships of Agglomerated Instant Coffee. Journal of Food Process Engineering, 17, 383-400. 
Pugnaloni, L. A., Matia-Merino, L. \& Dickinson, E. (2005). Microstructure of acid-induced caseinate gels containing sucrose: Quantification from confocal microscopy and image analysis. Colloids and Surfaces B: Biointerfaces, 45, 211-217.

Quevedo, R, Carlos, L.-G., Aguilera, J. M. \& Cadoche, L. (2002). Description of food surface and microstructural changes using fractal image texture analysis. Journal of Food Engineering, 53, 361371.

Robert, P., Devaux, M.-F., Bertrand, D. (1996). Beyond prediction: extracting relevant information from near infrared spectra. Journal of Near Infrared Spectroscopy, 4, 75-84.

Roueff, F. \& Lévy Véhel, J. (1998). A Regularization Approach to Fractional Dimension Estimation. in Proceedings of Fractals 98, Malta.

Sarker, D. K., Bertrand, D., Chtioui, Y. \& Popineau, Y. (1998). Characterisation of foam properties using image analysis. Journal of Texture Studies, 29, 15-42.

Serra, J. (1982). Image Analysis and Mathematical Morphology. London: Academic Press.

Thibault, J.-F. (1979). Automatisation du dosage des substances pectiques par la méthode au bétahydroxydiphényl. Lebensmittel-Wissenschaft und Technologie, 12, 247-251

Thibault, J.-F. \& Rouau, X. (1990). Studies on enzymatic hydrolysis of polysacharides in sugar beet pulp. Carbohydrate Polymers, 13, 1-16.

Thibault, J.-F., Renard, C. M. G. C. \& Guillon, F. (1994). Physical and chemical analysis of dietary fibre in sugar beet and vegetables. In H.F. Linsken and J.-F. Jackson, Modern methods of plant Analysis, Vegetables and Vegetables Products, vol 16 (pp. 23-55). Berlin : Springer-Verlag.

Tollier, M.T. \& Robin, J.-P. (1979). Adaptation de la méthode à l'orcinol sulfurique au dosage automatique des glucides neutres totaux : conditions d'application aux extraits d'origine végétale. Annales de Technologie Agricole, 28, 1-15. 
Witt, W. \& Röthele, S. (1998). In-line laser diffraction with innovative sampling. In Proceedings of the $7^{\text {th }}$ European Symposium Particle Characterization PARTEC 98. Preprints II (pp. 611-624 ). NürnbergMesse GmbH. Nürnberg, March 10-12. 


\section{Legend of figures}

Figure 1: Torus reactor prototype

Figure 2: examples of images of beet pulp during enzymatic degradation. First row: without enzyme, second row: with cellulolytic enzymes, third row: with pectinolytic enzymes, fourth row: with both kind of enzymes. Left, middle, right: after 0, 6 and $24 \mathrm{~h}$ of degradation, respectively.

Figure 3: Numerical calculation of the regularization dimension using FRACLAB

Figure 4: solubilisation percentage for neutral sugars (a) and galacturonic acid (b). Square: reference experiment, diamond: cellulolytic enzymes, circle: pectinolytic enzymes, triangle: both enzymes.

Figure 5: Granulometric curves assessed using mathematical morphology. a: reference experiment, b: cellulolytic enzymes, c: pectinolytic enzymes, d: both enzymes.

Figure 6: Principal component analysis of granulometric curves. First principal scores according to time. Square: reference experiment, diamond: cellulolytic enzymes, circle: pectinolytic enzymes, triangle: both enzymes.

Figure 7: Evolution of the regularization dimension. a: reference experiment, b: cellulolytic enzymes, c: pectinolytic enzymes, d: both enzymes. (circle: Linf, square: Lsup).

Figure 8: Residual particles after $24 \mathrm{~h}$ reactions observed by confocal microscopy. Top left: reference experiment, top right: cellulolytic enzymes, bottom left: pectinolytic enzymes, bottom right: both enzymes. Size of images: $325 \mu \mathrm{m}$ x $325 \mu \mathrm{m}$.

\section{Legend of tables:}

Table 1: Sugar compositions expressed as percentage of dry matter of the raw sugar beet pulp and of residues obtained from different enzymatic degradations. 
Table 1

\begin{tabular}{llllll}
\hline & $\begin{array}{l}\text { raw sugar } \\
\text { beet pulp }\end{array}$ & $\begin{array}{l}\text { Without } \\
\text { enzyme }\end{array}$ & $\begin{array}{l}\text { Celluclast } \\
1.5 \mathrm{~L}\end{array}$ & SP584 & $\begin{array}{l}\text { SP584 } \\
\text { Celluclast 1.5L }\end{array}$ \\
\hline Rhamnose & 1.8 & 1.3 & 1.4 & 0.5 & 0.7 \\
Arabinose & 18.0 & 18.1 & 18.5 & 1.3 & 1.9 \\
Xylose & 1.3 & 1.3 & 1.2 & 1.6 & 2.3 \\
Mannose & 1.0 & 1.0 & 1.0 & 2.7 & 2.6 \\
Galactose & 4.7 & 4.8 & 5.3 & 1.3 & 1.6 \\
Glucose & 19.5 & 20.7 & 18.3 & 54.4 & 8.5 \\
Galacturonic acid & 18.9 & 18.5 & 18.4 & 2.1 & 4.0 \\
\hline
\end{tabular}


Figure 1
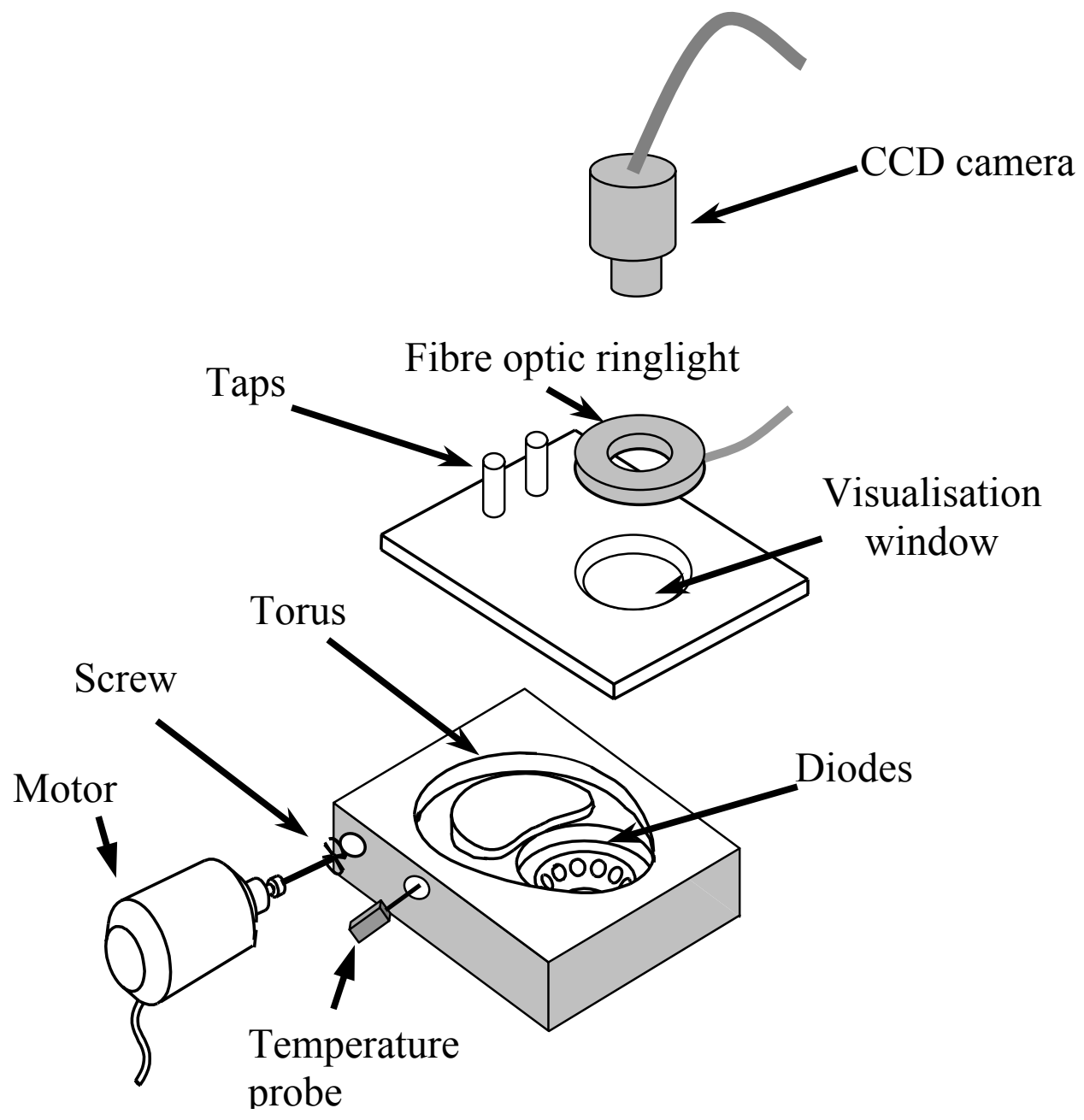
Figure 2.
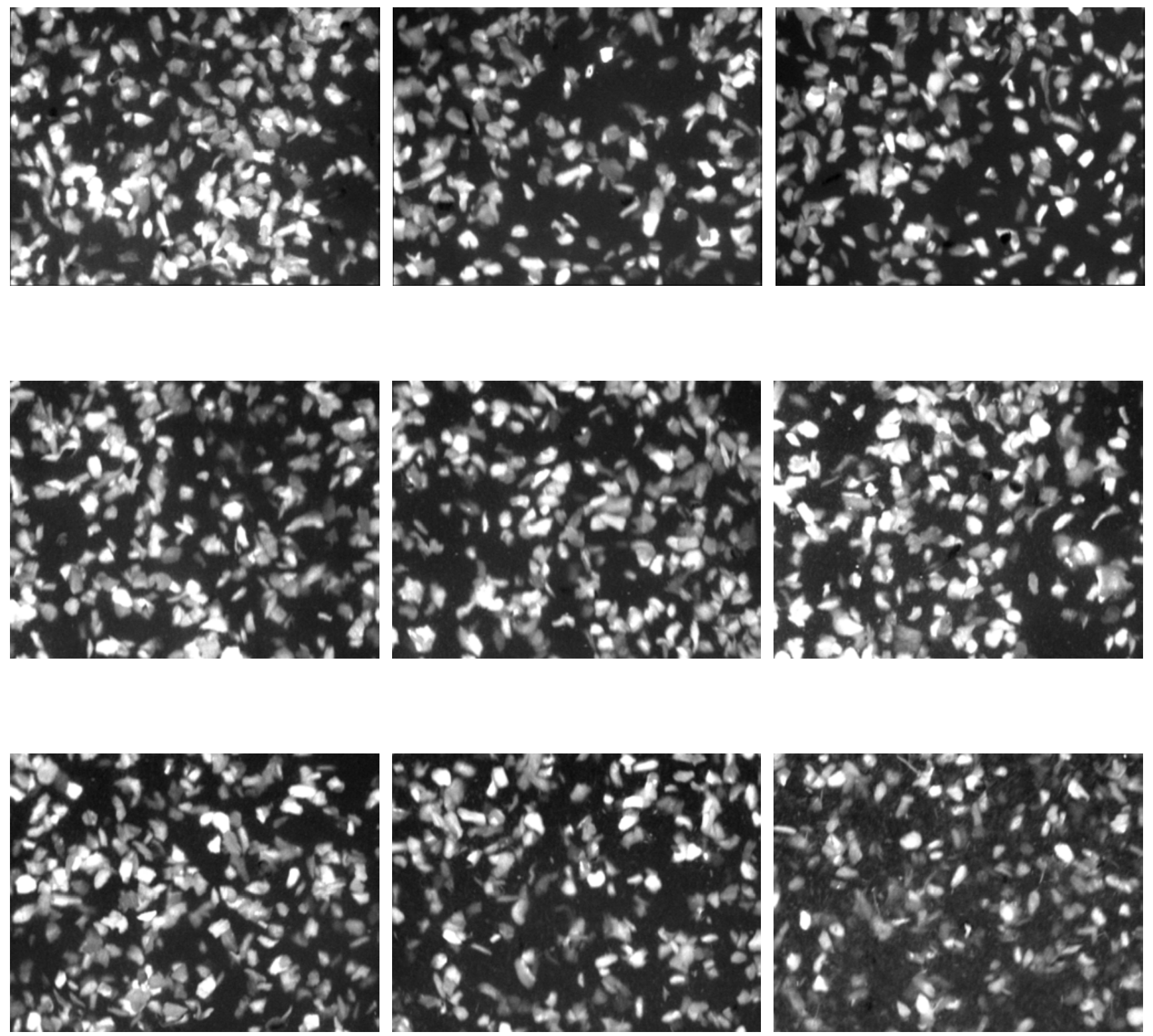

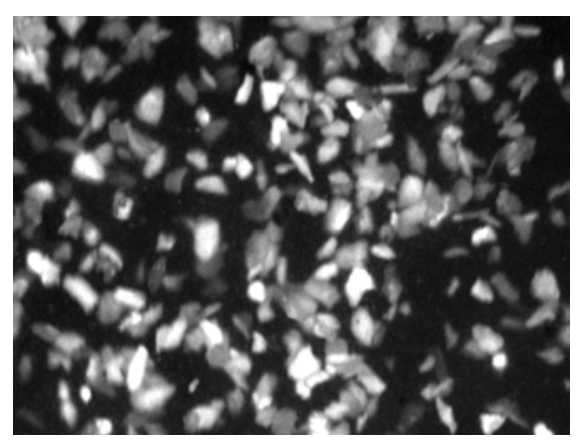

0

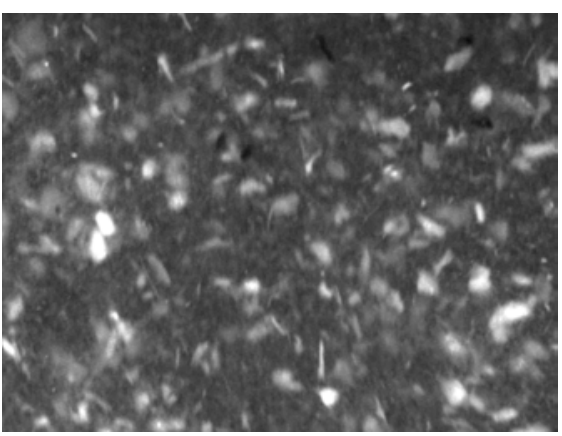

6h

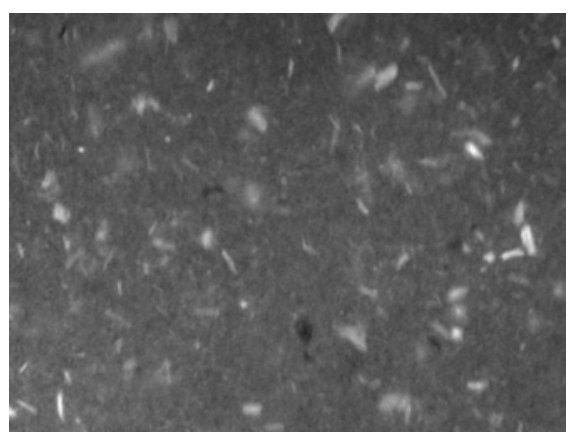

24h 
Figure 3 :

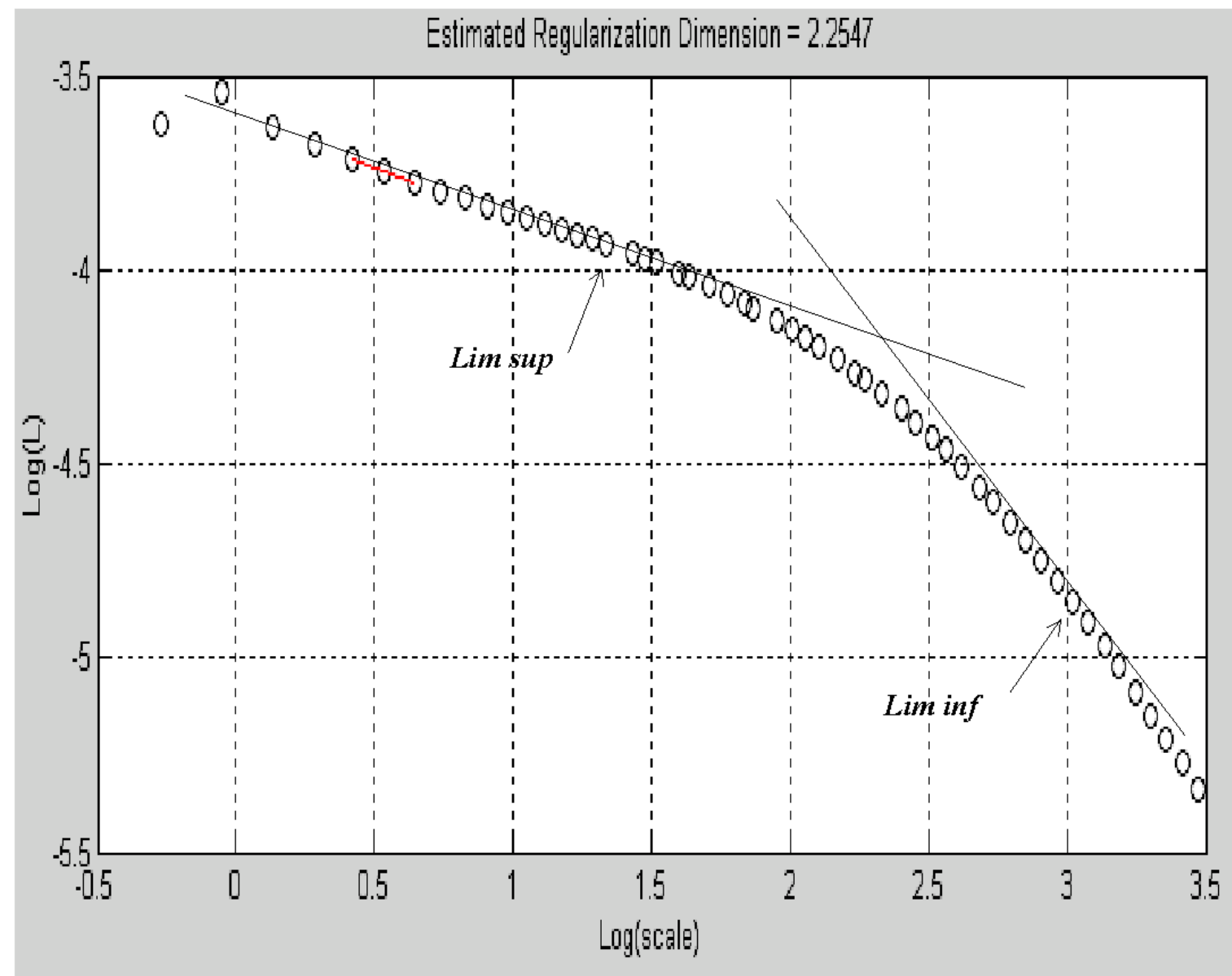


Figure 4a :

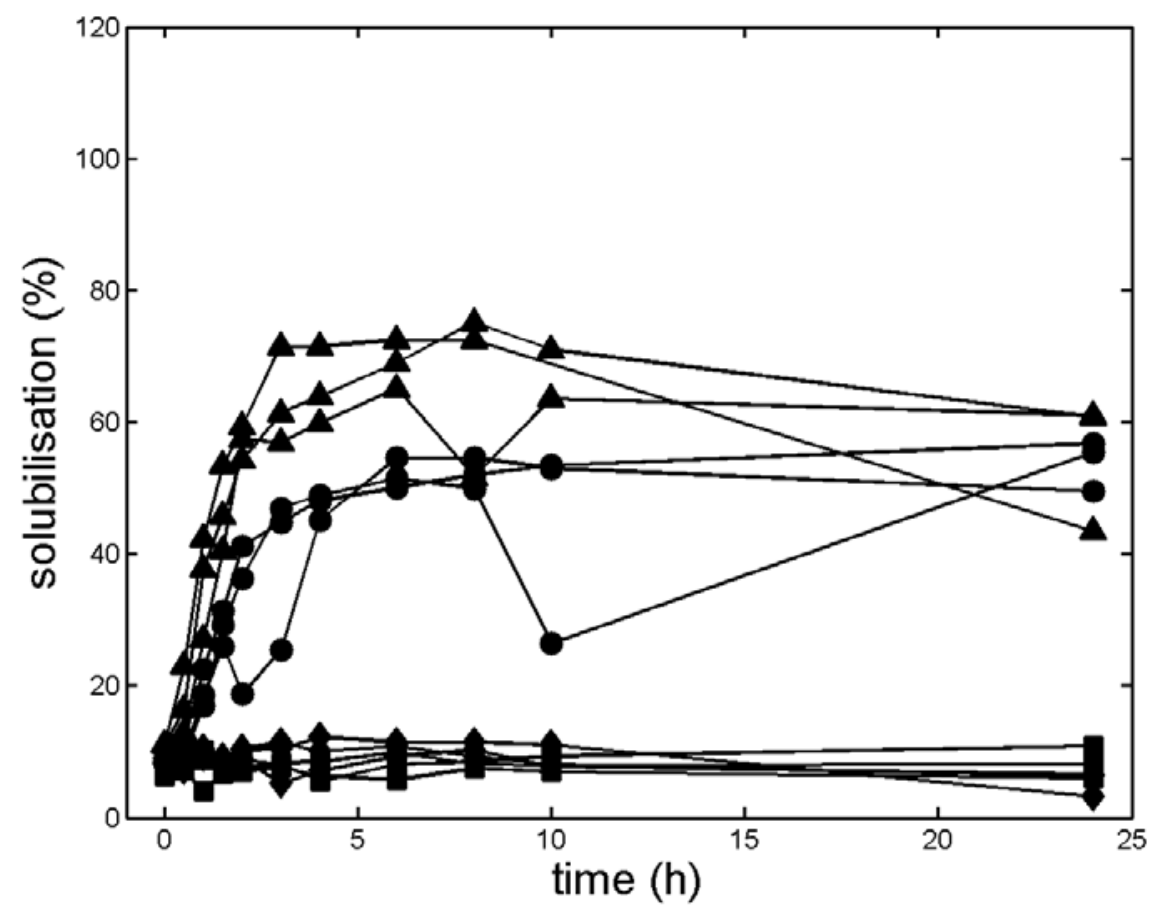

Figure $4 b$

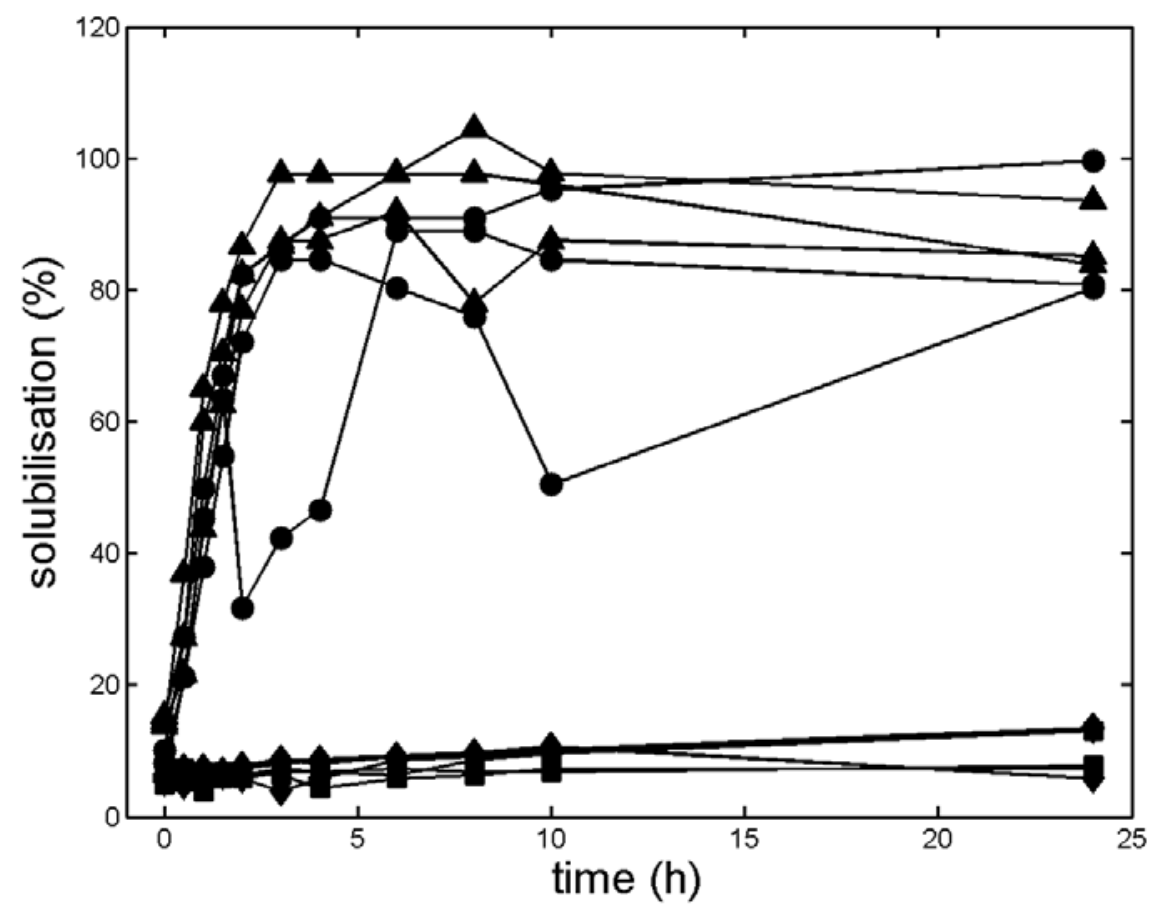


Figures 5 a et $5 b$
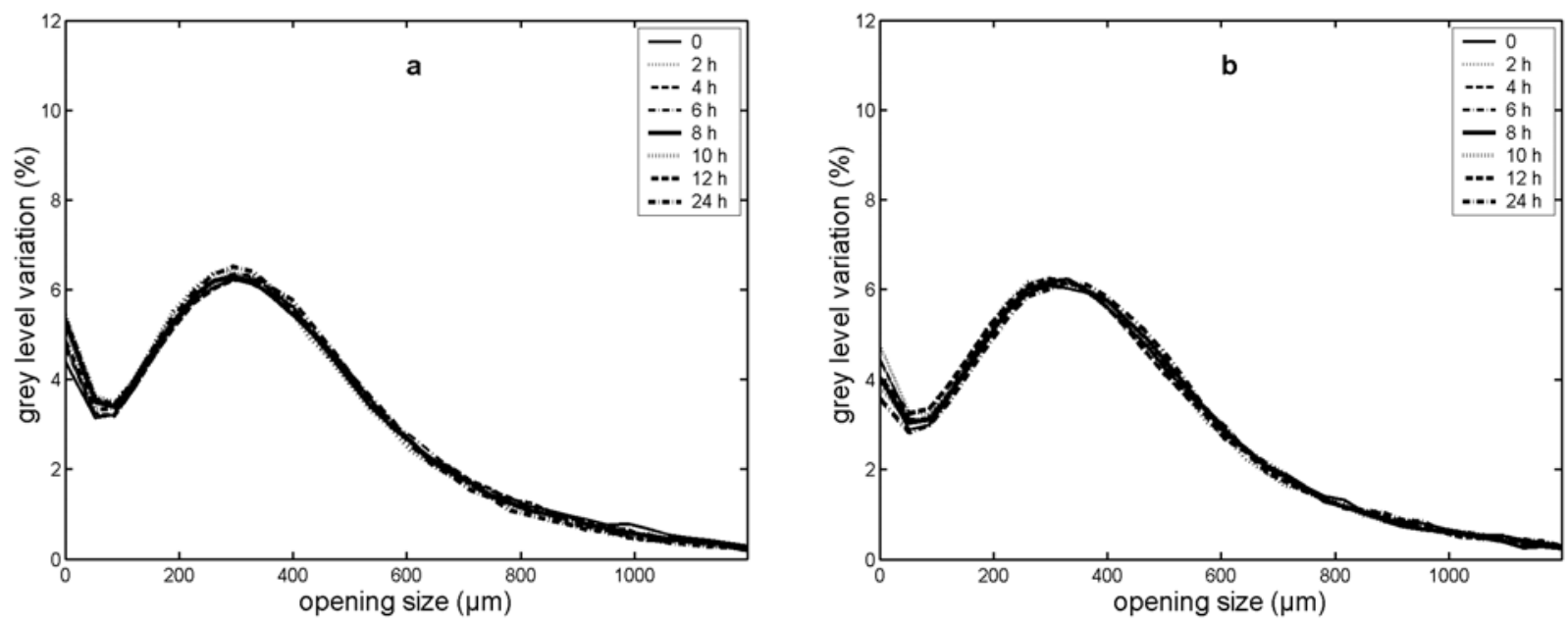

Figures $5 \mathrm{c}$ et $5 \mathrm{~d}$.
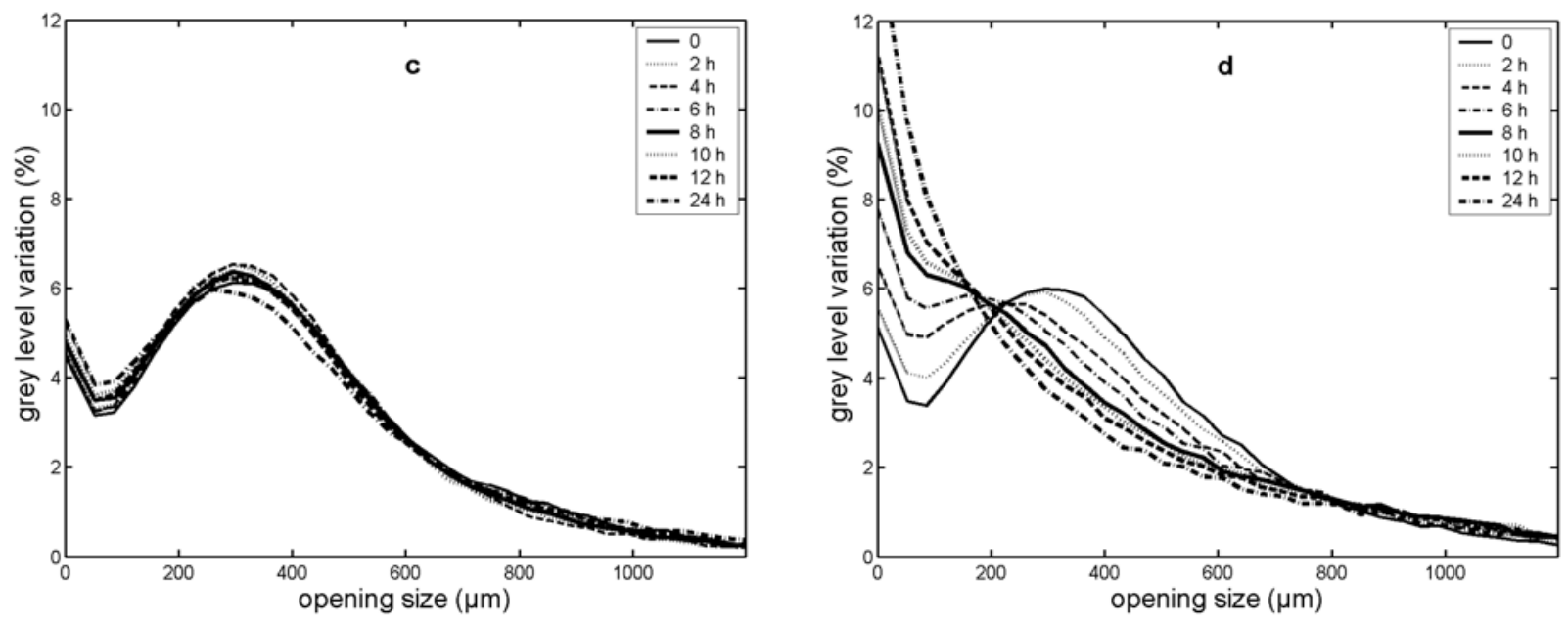
Figure 6 :

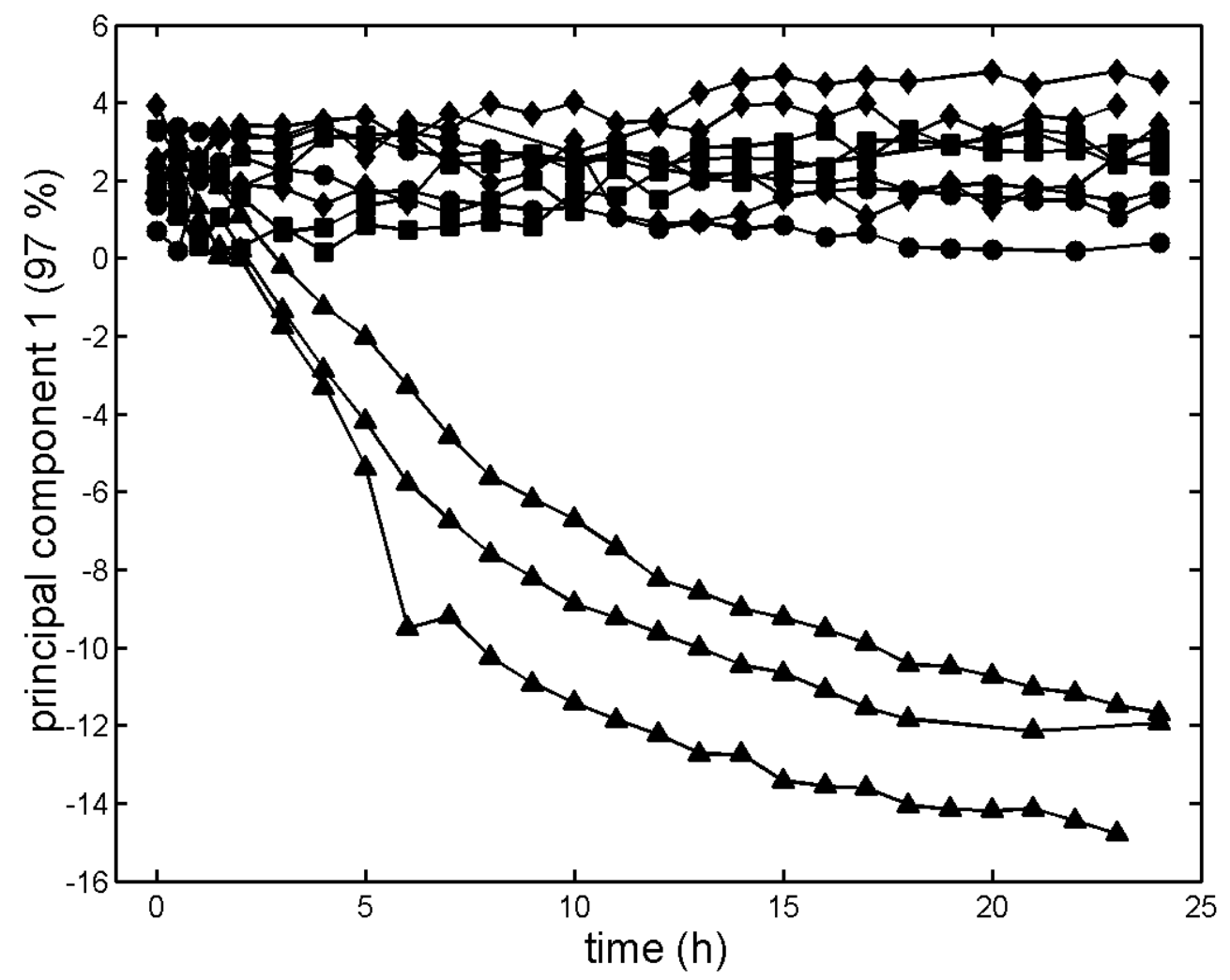


Figures $7 \mathrm{a}$ et $7 \mathrm{~b}$
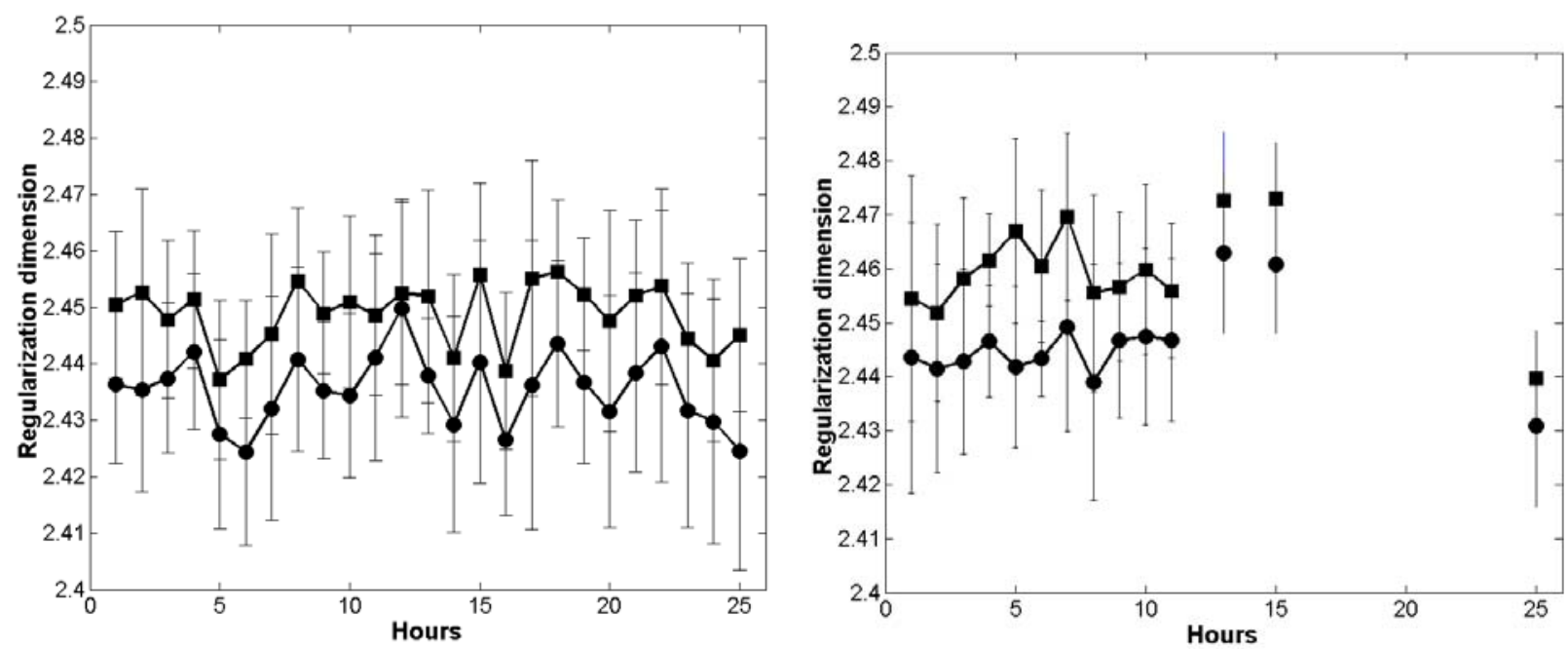

Figure $7 \mathrm{c}$ et $7 d$
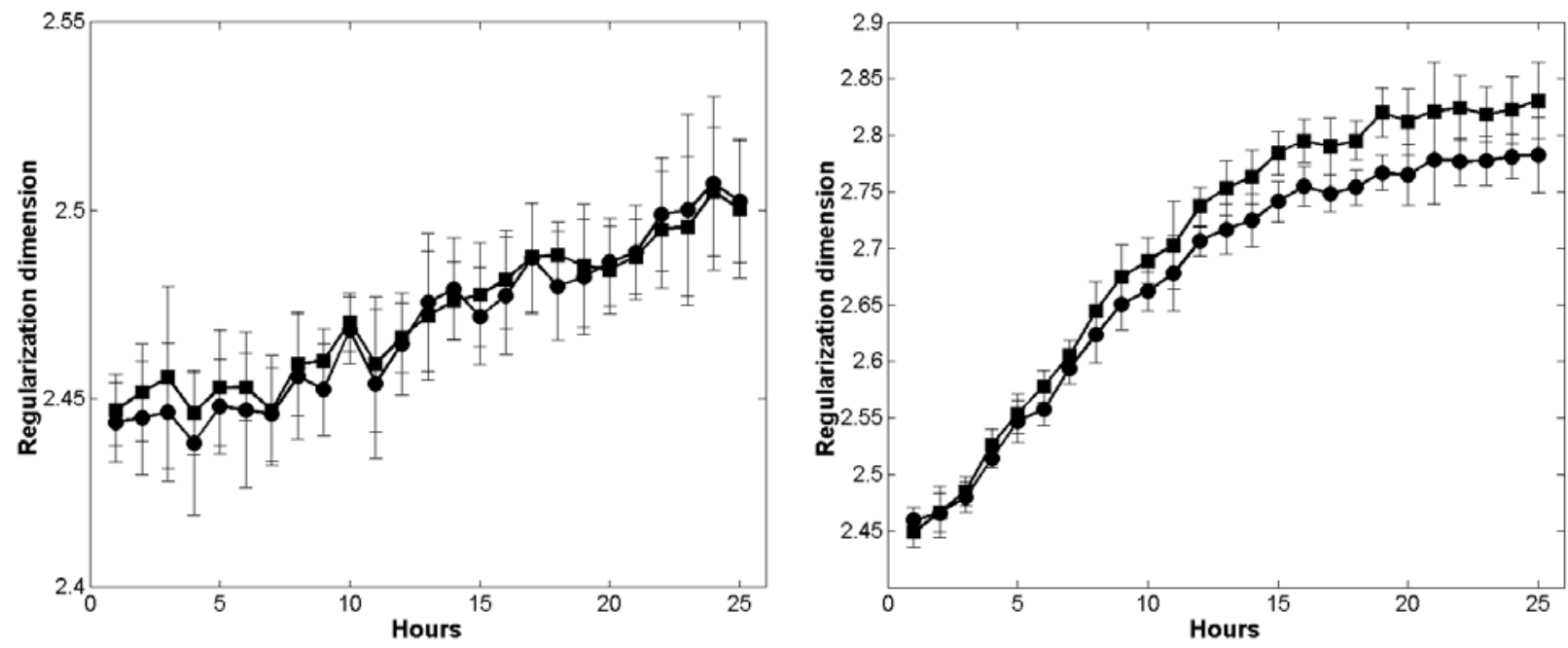
Figure 8
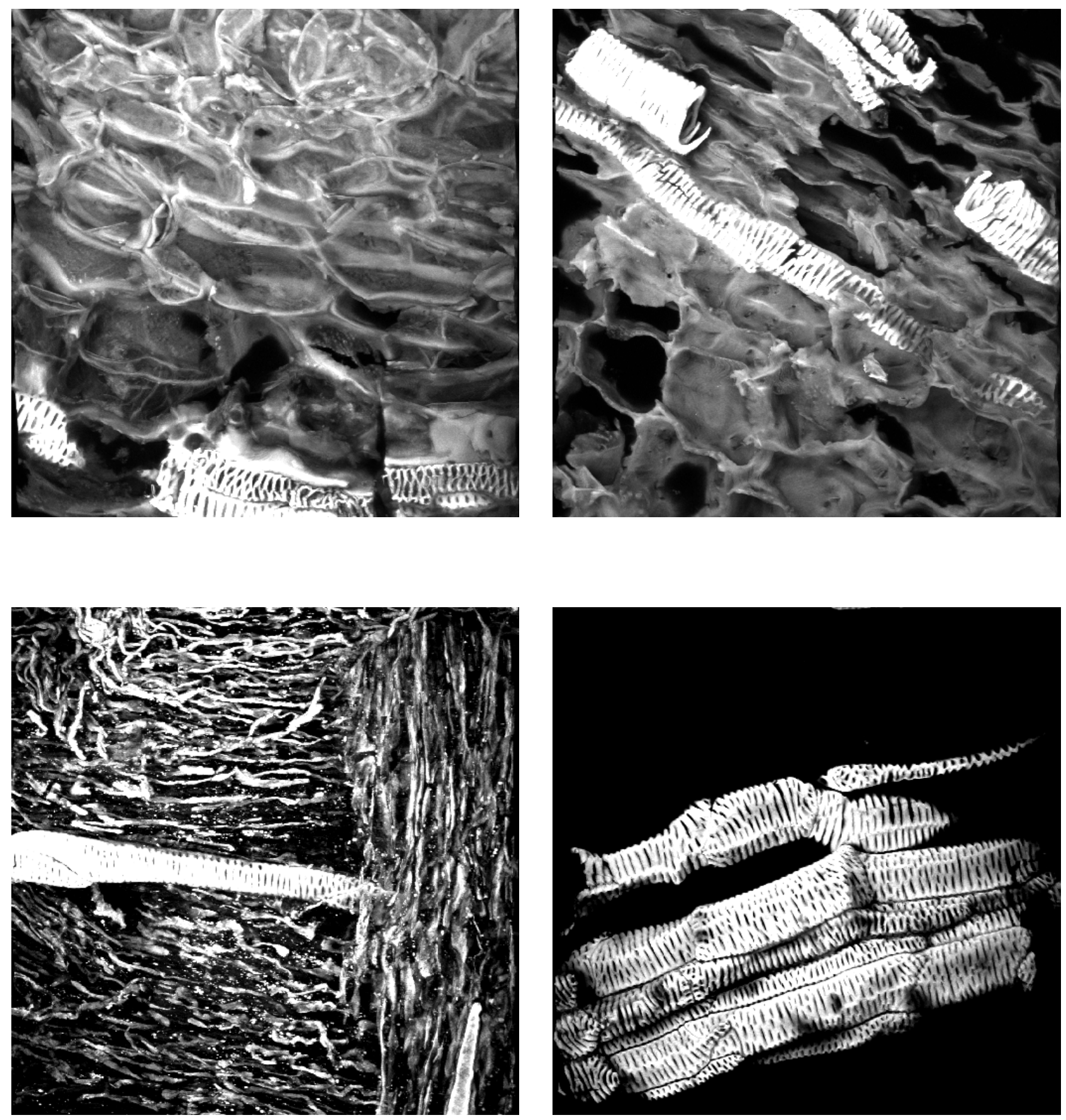